\title{
Ergenlerin Bağlanma Stilleri ile İnternet Bağımlılık Düzeyleri Arasındaki İlişkinin İncelenmesi
}

$* * *$

\section{Analysis of The Relationship Between Attachment Styles and Internet Addiction Levels of Adolescents}

\author{
Dr. Öğr. Üyesi Gülin Yazıcı Çelebi \\ Gümüşhane Üniversitesi, EF, gycelebi@gumushane.edu.tr \\ ORCID: 0000-0002-6779-9123 \\ Öğr. Bülent Çelebi \\ Trabzon Gazi Anadolu Lisesi, bcelebi76@gmail.com \\ ORCID: 0000-0003-1033-3872
}

\begin{abstract}
Özet
Ergenlik dönemi, üzerinde en çok durulan ve araştırma yapılan gelişim dönemlerinden biridir ve bu dönemde yaşanacak duygusal zorlanmaların, beraberinde bazı davranışsal sorunları getireceği söylenebilir. Ergenlik döneminde kurulacak duygusal ilişkiler dönemin seyri üzerinde oldukça etkilidir. Anlamlı duygusal bağlar kurma eğilimi olarak tanımlanan bağlanma davranışının bu dönemde yaşanacak duygusal ilişkileri önemli ölçüde etkileyebileceği söylenebilir. Duygusal sorunların bağımlılıklara yatkınlık oluşturduğu bilinmektedir. Bu araştırmanın amacı da duygusal ilişkiler üzerinde etkili olan bağlanma stilleri ile internet bağımlılı̆̆ı arasındaki ilişkinin incelenmesidir. Araştırmanın verileri 2019 yılın içerisinde toplanmıştır. Veriler çeşitli liselerde öğrenim gören 316 lise öğrencisinden elde edilmiştir. Katılımcıların \%50 si kadın, \%50’si erkektir, çalışma grubunun yaş ortalaması 16,02 olarak hesaplanmıştır. Veri toplama aracı olarak kişisel bilgi formu, İlişki Ölçekleri Anketi ve Young İnternet Bağımlılığı Testi Kısa Formu kullanılmıştır. Verilerin analizinde SPSS 23 programı kullanılmıştır. Yapılan analizler bağlanma stilleri ile internet bağımlılığı arasında anlamlı bir ilişki olduğunu göstermektedir. Araştırmada ergenlerin bağlanma stilleri cinsiyet, anne-baba eğitim düzeyi, okul türü açısından da incelenmişti. Ergenlerin kayıtsız bağlanma stillerinini cinsiyet açısından farklılaştığı görülmüştür. Anne ve baba eğitim düzeyi açısından yapılan analizler sonucunda baba eğitim düzeyine göre güvenli ve kayıtsız bağlanma stillerinin, anne eğitim düzeyi açısından ise kayıtsız bağlanma stillerinin farklılaştı̆̆ bulunmuştur. Okul türü değişkenine yönelik yapılan analizler sonucunda kayıtsız ve saplantılı bağlanma stilleri açısından anlamlı farklılıklar olduğu belirlenmiştir.
\end{abstract}

Anahtar Kelimeler: İnternet Bağımlılı̆̆ı, Ergenlik, Bağlanma

JEL Sinıflandırması: I29

Abstract
Adolescence is one of the most emphasizedand researched development periodsand it can be said that emotional
difficulties that are experienced in this period will bring some behavioral problems. The emotional relationships to be
established in this period are quite effective on the course of the period. It can be said that attachment behavior, which
is defined as the tendency to establish meaningful emotional bonds, can significantly affect the emotional relations to
be experienced in this period. Emotional problems are known to predisposeto addictions. The purpose of this research
is to examine the relationship between attachment styles that affect emotional relationships and internet addiction.
The data of the research were collected in 2019 . The data were obtained from 316 high school student sstudying in
various high schools. (Kadin=158 $(\% 50 ; 16,06)$; Erkek=158 $(\% 50 ; 15,98)$. Personal data form, attachment styles scale
and Young Internet Addiction Scale Short Form were used as data collection tools. SPSS 23 program was used in the
analysis of the data. Analysis shows that there is a significant relationship between attachment styles and internet
addiction. In the study, attachment styles of adolescents were also examined in terms of demographic variables. It was 
observed that the dismissive-avoidant attachment styles of adolescents differ in terms of the gender variable. As a result of the analyzes performed towards parents' educational level, it was found that the secure and dismissiveavoidant attachment styles differ according to the father's educational level and the dismissive-avoidant attachment styles differ in terms of the mother's educational level. As a result of the analyzes performed towards the school type variable, it was determined that there were significant differences in terms of dismissive-avoidant and preoccupied attachment styles.

Keywords: Internet Addiction, Adolescence, Attachment

JEL Classification: I29

\section{GİRIŞ}

Ergenlik; insan hayatı gelişim dönemleri açısından değerlendirildiğinde en önemli dönemlerden biri olarak kabul edilmektedir (Yavuzer, 2011). Bu dönemde birey birçok alanda mücadele vermekte, biryandan bedeninde yaşadığı hızlı ve ani değişimlere uyum sağlamaya çalışırken, bir yandan da duygusal ve sosyal alanda mücadeleler vermekte ve çeşitli baskılara maruz kalmaktadır (Çetinkaya, 2013). Ergenlikle ilgili çeşitli tanımlamalar yapılmış ve yapılmaktadır. Bu tanımların bazıları ise çok eskilere dayanmaktadır. İlk kez 15. yüzyılda kullanılan ergenlik terimi; olgunlaşmak / büyümek anlamına gelen Latince, adolescere kelimesinden türetilmiştir (Muuss, 1990). İlk ortaya çıkışından bugüne hemen her dönemde üzerinde çeşitli çalışmalar ve tanımlamalar yapılmıştır. Erikson (1993) geliştirmiş olduğu psikososyal gelişim kuramında ergenlik dönemini kalıtsal bir olgunlaşma temel planının, kimlik karmaşasına karşı kaçınılmaz psikososyal krizle sonuçlandığı bir dönem olarak ele almıştır. Kulaksızoğlu (2013) ise, yaptığı tanımlamada ergenliğgi; insanda fiziksel büyümenin yanı sıra hormonal, cinsel, sosyal, duygusal, kişisel ve zihinsel değişimlerin ve gelişmelerin yaşandığı buluğa erme ile başlayan ve beden büyümesinin bitmesiyle sonlanan bir dönem olarak tanımlamaktadır. Parman (2008) ise, ergenliği; başkalaşım, değişim, dönüşüm ve büyümek şeklinde özetlemektedir. Tanımların ortak paydasının her alanda görülen hızlı değişim ve dönüşüm olduğu söylenebilir. Ergenlikte ana amaçlardan biri, kimlik oluşturmadır ve bu süreçte bireyin psikososyal gelişimi önem kazanmaktadır. Psikososyal gelişim üzerinde etkisi olan birçok faktör vardır. Bunların başında da bireyin bebeklikten bu yana anne-babasıyla kurmuş olduğu ilişkiler gelmektedir. Anne-babayla kurulan ilişkinin niteliği, ergenlik döneminde oldukça önemlidir. Ebeveynlerle kurulan ilişkinin güvene dayalı olmas1, psikososyal gelişim üzerinde olumlu etkilere sahiptir. Ebeveynlerle kurulan ilişkilerin güvene dayanmasının ön koşullarından biri, güvenli bir bağlanma ilişkisi geliştirmiş olmalarıdır. İnsanların önem verdikleri kişilere karşı hissettikleri güçlü duygusal bağlar olarak tanımlanan bağlanma kavramı, önem verilen kişilerle birlikteyken keyif alınmasını, zor durumlardaysa rahatlamayı sağlayan güçlü bir duygusal sistem oluşturmaktadır (Ainsworth, 1991; Bowlby, 2012).

İngiliz Psikanalist John Bowlby (1969) tarafından geliştirilmiş olan bağlanma kuramına göre, bağlanmanın temelleri bebeklik döneminde atılmakta fakat tamamlanmamakta ve kişinin tüm yaşamı boyunca devam etmektedir. Bowlby (2012) bu durumu bağlanma, insan ilişkilerini "beşikten mezara" belirlemektedir şeklinde özetlemektedir. Bağlanma ile ilgili en bilinen çalışmayı gerçekleştiren Bartholomew ve Horowitz (1991) bağlanmayı dört boyutta ele almıştırlar. Bu boyutlar güvenli, saplantılı, kayıtsız ve korkulu olarak ifade edilmektedir.

Güvenli bağlanma: Güvenli bağlanma stiline sahip bireylerin hem benlik hem de başkaları modelleri olumludur. Bir başka deyişle kendilerini sevilmeye değer karşılarındakini de güvenilmeye değer olarak görmektedirler. Özgüvenleri ve benlik saygıları yüksektir, karşılarındaki insanlara rahatça güven duydukları için bu bireyleri sıcak, duyarlı ve kabul edici bulmaya eğilimlidirler (BartholomewveHorowitz, 1991). Kısaca güvenli bağlanma ilişkisine sahip bireyler, yakın ilişkilerini yönlendirme konusunda oldukça rahattırlar ve kendilerini değerli hissederler.

Korkulu bağlanma biçimi: Güvenli bağlanma stilinin tam tersi olan güvensiz bağlanma stilinde hem benlik hem de başkaları modelleri olumsuzdur. Yani kendilerini sevilmeye, başkalarını da güvenilmeye değer 
görmezler. Özgüvenleri düşüktür ve çekingendirler. Reddedilme korkusu ile yakın ilişkilerden kaçınma eğilimindedirler.

Saplantılı bağlanma: Bu bağlanma stiline sahip bireylerde benlik modelleri olumsuz, başkaları modelleri olumludur. Bu modeller nedeniyle de karşılarındaki kişiler tarafından sevilme, güvenilme ve kabul edilme konusunda kaygı yaşamaktadırlar (Bartholomew \& Shaver, 1998). Bu kaygıdan dolayı yaşadıkları değersizlik hissi onların yakın ilişkilerde ısrarcı olmalarına, kişisel değerlilik ve kişisel yeterliliği sağlamak için yoğun çaba göstermelerine sebep olabilmektedir. Bu ssrar zaman zaman ters tepmekte ve insanların kendilerinden uzaklaşmasına yol açabilmektedir. Aldıkları bu sonuç olumsuz benlik modelini pekiştirebilmekte ve kısırdöngüye yol açabilmektedir.

Kayıtsız bağlanma biçimi: Saplantılı bağlanma stilinin tam tersi olan kayıtsız bağlanma stilinde bireylerin benlik modelleri olumlu, başkaları modelleri olumsuzdur. Bu nedenle de yakın ilişkilere yönelik yüksek kaçınma davranışı göstermektedirler. Özerkliklerine aşırı önem veren bu kişiler, yakın ilişkilerin gerekliliğini reddetme eğilimdedirler (Bartholomew \& Horowitz, 1991).

Ergenlik dönemi bağlanma açısından bir geçiş dönemidir. Bebeklikte ilk bakım verenle kurulan ve daha çok fiziksel ihtiyaçların karşılanması prensibi ile işleyen bağlanma örüntüsü, ergenlik döneminde daha çok duygusal ihtiyaçlar halinde ortaya çıkmakta, bağlanılan kişiyle duyguları, kaygıları ya da korkuları paylaşmak şeklinde yaşanabilmektedir (Damarl1, 2006). Ergenler bu dönemde ebeveynlerinden başkalarına genellikle de akranlarına doğru yönelim göstermektedir. Ancak bu ilişkiler üzerinde erken bağlanma örüntülerinin kalıcı ve güçlü bir etki bıraktığı düşünülmektedir (Allen \& Land,1999). Alanyazına bakıldığında, güvenli bağlanma stiline sahip bireylerin daha az psikolojik sorunlar yaşadıkları, güvensiz bağlanma stiline sahip bireylerin ise daha fazla psikolojik sorun yaşadıkları görülmektedir. (Bar-Haim, Dan, Eshel \& Sagi-Schwartz ,2007; Hamarta, 2004; Vertue, 2003).

Ergenlik dönemi, psikolojik sorunların yanı sıra riskli davranışlar açısından da kritik bir dönem olarak değerlendirilmekte, heyecan arama davranışlarının artmasının bağımlılıklara yatkınlığı arttırdığı ifade edilmektedir (Donohue, Urgelles \& Fayeghi, 2013; Griffiths, 2005). Güvenli bağlanmayan ergenlerin özkontrol algılarının düşük olduğu sonucuna ulaşılmıştır (Tangney, Baumeister \& Boone, 2004). Çalışmalar öz-kontrol algısının düşük olmasının bireyi internet bağımlılığına daha yatkın hale getirebildiğini göstermektedir (Cao, Su, Liu \& Gao,2007; Ko vd., 2009; Milani, Osualdella \& Blasio, 2009). İnternet bilgiye erişimiveiletişim kurmayı kolaylaştırması ve çeşitli eğlence fırsatları sunması nedeniyle günlük hayatın bir parçası haline gelmiştir. İnterneti yoğun olarak kullanan grupların başında ergenler gelmektedir (Kutlu, Savcı, Demir ve Aysan, 2016). Başlangıçta sağladığı faydalar açısından yararlı görülen internet amacını aşan ve kontrolsüz kullanımlar nedeniyle çeşitli sorunlara yol açmaktadır. Uygunsuz içeriklere kolay erişim sağlanması, şiddet içeren içeriklere erişimin kontrolsüz olması, sanal ortamlarda kurulan ilişkilerin siberzorbalık tehdidi içerebilmesi, zamanın kontorlsüz geçirilmesi nedeniyle sorumlulukların aksatılması internetin yol açacağı zararlara verilebilecek çok sayıda örnekten sadece birkaçıdır. $\mathrm{Bu}$ zararların daha da tehlikeli hale gelmesine yol açacak faktörlerin başında da internet bağımlılığı gelmektedir. Yapılan araştırmalar internet kullanım sıklığının/süresinin artmasının bağımlılığa yol açtığ 1 ifade edilmektedir (Savcı \& Aysan, 2017). İnternet bağımlılığının standart bir tanımı olmadığı halde, araştırmacılar arasında böyle bir olgunun varlı̆̆ kabul görmektedir (Chou, Condron \& Belland, 2005). Young (1998) ise bağımlı internet kullanımını, "sarhoş edici bir madde alımını içermeyen bir dürtü kontrol bozukluğu" şeklinde tanımlamaktadır. Dünya sağlı örgütü online oyun ve online kumar bağımlılığını ICD 11'dehastalık olarak ele almaktadır. Ayrıca Oyun Oynama Bozukluğu Haziran 2018'de, Uluslararas1 Hastalık Sınıflandırması (International Classification of Diseases-11 (ICD-11)'de, "Gaming Disorder" olarak yerini almıştır. Oyun oynama bozukluğu, çevrimiçi veya çevrimdışı olarak gösterilebilecek sürekli veya tekrarlayan oyun davranışı ("dijital oyun" veya "video oyun") ile karakterizedir (Sağlık Bakanlığı, 2018). Young (1998)'e göre internet bağımlıları internet kullanımını kontrol etme, durdurma konusunda 
sorun yaşayan ve bu girişimler sırasında; rahatsızlık, ruh halinde değişkenlik, huzursuzluk hissetmekte gibi örüntüler sergilemektedirler. İnternet bağımlılığı özetle aşırı internet kullanılması ve bunun önüne geçilememesi, yoksunluk halinde aşırı sinir ve saldırganlık belirtilerinin olması hali olarak tanımlanmaktadır. Araştırmalar yalnızlığın ve doyurucu sosyal ilişkileri sahip olmamanın internet bağımlılığının en önemli nedenlerinden biri olduğunu ortaya koymaktadır (Davis, 2001; Odacı \& Kalkan, 2010; Takunaga \& Rains, 2010). İnsanların diğerleri ile kuracakları ilişkiler üzerinde önemli bir etkisi olan bağlanma stillerinin sosyalleşme becerileri üzerinde etkili olduğu düşünülmektedir. Bu nedenle bağlanma stillerinin internet bağımlılığı üzerinde etkili olacağı düşünülmektedir. Alanyazına bakıldığında bağlanma stilleri internet bağımlılığını etkileyen kritik faktörlerden biri olarak değerlendirilmektedir (Shin, Kim \& Jang, 2011).

İnternet bağımlılığı gün geçtikçe daha büyük bir tehdit haline gelmektedir (Doğan, 2013). İnternet bağımlılığına etki edebilecek faktörlerin belirlenmesi, bağımlılı̆̆ın önlemesine yönelik yapılacak çalışmaların belirlenmesine ve öncelik verilecek konulara karar verilmesine katkı sağlayacağ 1 düşünülmektedir. $\mathrm{Bu}$ araştırmadan elde edilecek sonuçların da internet bağımlılığına yönelik yapılacak önleyici çalışmalara katkı sağlayacağ d düşünülmektedir. Bu sebeple bu araştırmanın amacı ergenlerin bağlanma stilleri ile internet bağımlılığı düzeyleri arasındaki ilişkinin incelenmesidir. Araştırmada ayrıca ergenlerin bağlanma stilleri cinsiyet, anne-abab eğitim düzeyi, okul türü değişkenleri açısından da incelenmektedir.

Araştırma soruları;

- Ergenlerin bağlanma stilleri ile internet bağımlılık düzeyleri arasında bir ilişki var mıdır?

- Ergenlerin bağlanma stilleri cinsiyet açısından farklılaşmakta mıdır?

- Ergenlerin bağlanma stilleri okul türü açısından farklılaşmakta mıdır?

- Ergenlerin bağlanma stilleri anne ve baba eğitim durumu açısından farklılaşmakta mıdır?

\section{YÖNTEM}

\subsection{Araştırmanın Modeli}

$\mathrm{Bu}$ araştırma nicel araştırma yaklaşımlarından korelasyonel desene dayalı olarak tasarlanmıştır. İlişkisel tarama modelleri iki ve daha çok sayıdaki değişken arasında birlikte değişim varlığını ve derecesini belirlemeyi amaçlayan araştırma modelleridir (Fraenkel, Wallen \& Hyun, 2015; Karasar, 2009).

\section{2. Çalışma Grubu}

Araştırmanın çalışma grubunu 2019 yılında farklı okul türlerinde öğrenim gören 158 kız ve 158 erkek toplam 316 lise öğrencisi oluşturmaktadır. Çalışma grubunun 158'i kadın (\%50) 158'i erkektir (\%50). Katılımcılar 14-18 yaşları arasındadır ve örneklemin yaş ortalaması 16,02 dir.

Tablo 1. Çalışma grubuna ilişkin demografik bilgiler

\begin{tabular}{|c|c|c|c|c|c|c|c|}
\hline Değişkenler & Gruplar & $\mathrm{f}$ & $\%$ & Değişkenler & Gruplar & $\mathrm{f}$ & $\%$ \\
\hline \multirow{2}{*}{ Cinsiyet } & Kadın & 158 & 50 & \multirow{4}{*}{ Baba Eğitim Durumu } & İlkokul & 55 & 17.4 \\
\hline & Erkek & 158 & 50 & & Ortaokul & 60 & 19 \\
\hline \multirow{5}{*}{ Okul Türü } & Anadolu Lisesi & 81 & 25.6 & & & 96 & 30.4 \\
\hline & Meslek Lisesi & 58 & 18.4 & & Üniversite & 105 & 33.2 \\
\hline & Fen Lisesi & 60 & 19 & \multirow{3}{*}{ Anne Eğitim Durumu } & İlkokul & 89 & 28.2 \\
\hline & Sosyal Bilimler & 51 & 16.1 & & Ortaokul & 67 & 21.2 \\
\hline & And İmam H. Lisesi & 66 & 20.9 & & $\begin{array}{l}\text { Lise } \\
\text { Üniversite }\end{array}$ & $\begin{array}{l}84 \\
76\end{array}$ & $\begin{array}{l}26.6 \\
24.1\end{array}$ \\
\hline
\end{tabular}




\subsection{Veri Toplama Araçları}

Ergenlerin bağlanma stillerini belirlemek amacıyla Sümer ve Güngör (1999) tarafindan geliştirilen "İlişki ölçekleri anketi", internet bağımlılık düzeylerini ölçmek için Kutlu vd. (2016) tarafından uyarlanan "Young İnternet Bağımlılığı Testi Kısa Formu" kullanılmıştır. Çalışma grubunun demografik bilgileri araştırmacılar tarafından hazırlanan kişilsel bilgi formu ile toplanmıştır.

\subsection{1. İlişsi Ölçekleri Anketi (İÖA)}

Türkçe'ye uyarlaması Sümer ve Güngör (1999) tarafından yapılan ölçeğin orjinaliGriffin ve Bartholomew (1994) tarafından geliştirilmiştir. Dörtlü bağlanma modeline göre hazırlanan ölçek 17 maddeden oluşmaktadır. Her bir bağlanma stilinin bir alt boyuta karşılık geldiği ölçekte, katılımcılar hangi bağlanma stilinde en yüksek puan aldıysa o grupta değerlendirilmektedir. İÖA alt ölçeklerinin cronbachalfa değerleri .41 ile .71 arasında değişmektedir (Sümer \& Güngör, 1999).

\subsubsection{Young İnternet Bağımııı̆ı Testi Kısa Formu}

Pawlikowski, Altstötter-Gleich ve Brand (2013) tarafından kısa forma dönüştürülen ölçeğin ilk hali Young (1998) tarafından geliştirilmiştir. 12 maddeden oluşan 5'li Likert tipindeki ölçeğin Türkçe uyarlaması Kutlu vd. (2016) tarafından hem ergen hem de üniversite öğrencileri üzerinde yapılmıştır. Ölçekten alınan puan yükseldikçe internet bağımlılığı düzeyi de yükselmektedir. Ölçeğin güvenilirlik çalışmalarında, cronbach alfa iç tutarlık katsayısı ergenlerde .86 olarak bulunmuştur (Kutlu vd., 2016).

\subsubsection{Kişisel Bilgi Formu}

Araştırmacılar tarafindan hazırlanan kişisel bilgi formunda, cinsiyet, yaş, okul türü, anne ve baba eğitim düzeyine ilişkin bilgiler yer almaktadır.

\section{4. İşlem}

Kullanılacak veri toplama araçları için ölçeklerin uyarlama çalışmasını yapan kişilerden ve uygulama yapılacak okul yetkililerinden gerekli izinler alınmıştır. Veriler 2019 yılı içersindearaştırmacı tarafından okullara bizzat gidilerek gönüllü öğrencilerden 3 ay içinde toplanmıştır. Toplam 334 öğrenciye form dağıtılmış, eksik ve hatalı doldurulan 18 form değerlendirmeye alınmamış ve 316 kişilik bir veri seti elde edilmiştir.

\subsection{Verilerin Analizi}

Verilerin analizinde Spss 23 programı kullanılmıştır. Analizlere başlamadan önce verilerin normal dağılım sayıltısını karşılayıp karşılamadığına ilişkin basıklık ve çarpıklık katsayılarına bakılmış 1.0 ve +1.0 aralığında değişmekte oldukları yani verilerin normal dağılım gösterdiği görülmüştür. Bu sonuçtan hareketle verilerin analizinde parametrik tekniklerin kullanılmasına karar verilmiştir (Büyüköztürk, Çokluk \& Şekercioğlu, 2011). Verilerin analizinde ergenlerin internet bağımlılıkdüzeyleri ile bağlanma stilleri arasındaki ilişkinin belirlenmesinde Pearson korelasyon analizi, bağlanma stillerinin demografik değişkenlere göre farklılaşıp farklılaşmadığı belirlemek için bağımsız gruplar t-testi ile tek yönlü varyans analizi; farklılıkların kaynağını test etmek için ise Benferronitesti kullanılmıştır (Büyüköztürk, 2014).

\section{BULGULAR}

$\mathrm{Bu}$ bölümde bağlanma stilleri ile internet bağımlılı̆̆ı arasındaki ilişkilerin yanı sıra, bağlanma stillerinin cinsiyet, okul türü, anne-baba eğitim düzeyi açısından farklılaşma durumları incelenmektedir. 
Tablo 2. Bağlanma stilleri ile internet bağımlılı̆̆ı arasındaki ilişkiye yönelik korelasyon analizi

\begin{tabular}{lccccccc}
\hline & $\overline{\mathrm{X}}$ & $\mathrm{SS}$ & 1 & 2 & 3 & 4 & 5 \\
\hline 1. Korkulu Bağlanma & 16.49 & 4.88 & 1 & & & & \\
2. Kayıtsız Bağlanma & 22.47 & 4.80 & $.27^{* *}$ & 1 & & & \\
3. Güvenli Bağlanma & 20.77 & 4.31 & $-.12^{*}$ & -.08 & 1 & & \\
4. Saplantılı Bağlanma & 14.86 & 4.59 & $.11^{*}$ & $.16^{* *}$ & -.04 & 1 & \\
5. İnternet Bağımlılığı & 28.08 & 8.67 & .03 & -.06 & .02 & $.37^{* *}$ & 1 \\
\hline \multicolumn{7}{c}{$* 0 . \mathrm{p}<.05 * * \mathrm{p}<.01$}
\end{tabular}

Korelasyon analizi sonuçlarına göre, internet bağımlılığı ile saplantılı bağlanma arasında $\left(\mathrm{r}=.37^{* *}, \mathrm{p}<.01\right)$ pozitif yönde anlamlı ve orta düzeyde bir ilişki olduğu belirlenmiştir.

Tablo 3. Ergenlerin cinsiyet açısından bağlanma stilleri puanlarının incelenmesine yönelik ilişkisiz örneklemler t-testi sonuçları

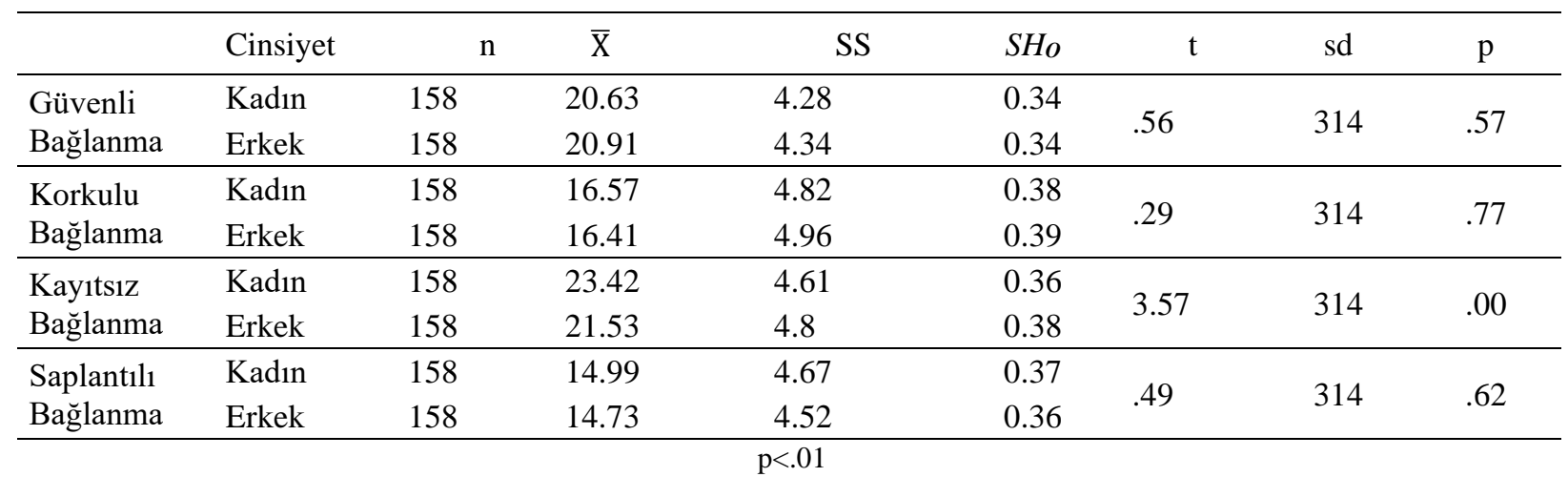

Tablo 3'de bağlanma stillerinin cinsiyet değişkeni açısından farklılaşma durumunun incelendiği ilişkisiz örneklem t-testi sonuçları görülmektedir. Tabloya bakıldığında güvenli, korkulu ve saplantılı bağlanma stilleri açısından kadınve erkekler arasında anlamlı bir fark olmadığı ancak kayıtsız bağlanma stili açısından

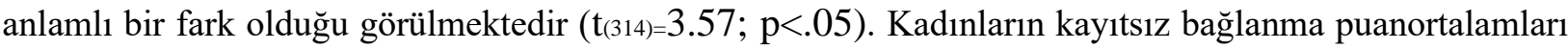
$(\overline{\mathrm{X}}=23.42)$ erkeklerin ortalamalarından $(\overline{\mathrm{X}}=21.53)$ daha yüksektir ve aralarındaki fark anlamlıdır. Genel olarak tabloya bakıldığında kadınların güvensiz bağlanma stillerinden daha yüksek puan aldıkları, güvenli bağlanma stilindeyse fark anlamlı olmasa da erkeklerin puanlarının daha yüksek olduğu görülmektedir.

Tablo 4. Ergenlerin baba eğitim düzeylerine göre bağlanma stilleri puanlarının incelenmesine ilişkin tek yönlü varyans analizi sonuçları

\begin{tabular}{|c|c|c|c|c|c|c|c|}
\hline & & KT & $\mathrm{sd}$ & KO & F & $\mathrm{p}$ & İkili karşılaştırma \\
\hline \multirow{2}{*}{$\begin{array}{l}\text { Güvenli } \\
\text { Bağlanma }\end{array}$} & Gruplararas1 & 171.14 & 3 & 57.04 & \multirow{2}{*}{3.14} & \multirow{2}{*}{0.03} & \multirow[b]{2}{*}{$1-3$} \\
\hline & Grup İçi & 5666.98 & 312 & 18.16 & & & \\
\hline \multirow{2}{*}{$\begin{array}{l}\text { Korkulu } \\
\text { Bağlanma }\end{array}$} & Gruplararas 1 & 39.58 & 3 & 13.19 & \multirow{2}{*}{0.55} & \multirow{2}{*}{0.65} & \multirow{2}{*}{ - } \\
\hline & Grup İçi & 7471.38 & 312 & 23.94 & & & \\
\hline \multirow{2}{*}{$\begin{array}{l}\text { Kayıtsız } \\
\text { Bağlanma }\end{array}$} & Gruplararas1 & 224.63 & 3 & 74.87 & \multirow{2}{*}{3.33} & \multirow{2}{*}{0.02} & \multirow[b]{2}{*}{$1-3$} \\
\hline & Grup İçi & 7020.10 & 312 & 22.50 & & & \\
\hline Saplantılı & Gruplararas1 & 69.59 & 3 & 23.19 & \multirow{2}{*}{1.10} & \multirow{2}{*}{0.35} & \multirow{2}{*}{ - } \\
\hline Bağlanma & Grup İçi & 6568.27 & 312 & 21.05 & & & \\
\hline
\end{tabular}


Tablo 4'te görüldüğü üzere babanın eğitim seviyesi açısından güvenli $\left(\mathrm{F}_{(3 ; 312)}=3.14 ; \mathrm{p}<.05\right)$ ve kayıtsız $\left(\mathrm{F}_{(3 ; 312)}=3.33 ; \mathrm{p}<.05\right)$ bağlanma stillerinin farklılaştığ 1 korkulu ve saplantılı bağlanma açısından ise babaların eğitim seviyesine göre bir farklılık olmadığı görülmektedir ( $p>.05)$. Farkın kaynağını belirlemek amacıyla yapılan benferoni testine göre farkın kaynağı ilkokul mezunları ile lise mezunları arasındaki farktır. Babası ilkokul mezun olan ergenlerin güvenli bağlanma boyutundan aldıkları puanın babası lise mezunu olanlardan daha yüksek olduğu, babası lise mezunu olanların ise kayıtsız bağlanma boyutundan aldıkları puanın babası ilkokul mezunu olanlardan daha yüksek olduğu görülmektedir.

Tablo 5. Ergenlerin anne eğitim düzeylerine göre bağlanma stilleri puanlarının incelenmesine ilişkin tek yönlü varyans analizi sonuçları

\begin{tabular}{|c|c|c|c|c|c|c|c|}
\hline & & KT & $\mathrm{sd}$ & KO & $\mathrm{F}$ & $\mathrm{p}$ & İkili karşılaşstırma \\
\hline \multirow{2}{*}{$\begin{array}{l}\text { Güvenli } \\
\text { Bağlanma }\end{array}$} & Gruplararas1 & 32.48 & 3 & 10.82 & \multirow{2}{*}{0.58} & \multirow{2}{*}{0.63} & \multirow{2}{*}{-} \\
\hline & Grup İçi & 5805.65 & 312 & 18.60 & & & \\
\hline \multirow{2}{*}{$\begin{array}{l}\text { Korkulu } \\
\text { Bağlanma }\end{array}$} & Gruplararas1 & 34.40 & 3 & 11.46 & \multirow{2}{*}{0.48} & \multirow{2}{*}{0.70} & \multirow{2}{*}{-} \\
\hline & Grup İçi & 7476.56 & 312 & 23.96 & & & \\
\hline \multirow{2}{*}{$\begin{array}{l}\text { Kayıtsız } \\
\text { Bağlanma }\end{array}$} & Gruplararası & 229.99 & 3 & 76.66 & \multirow{2}{*}{3.41} & \multirow{2}{*}{0.02} & \multirow{2}{*}{$1-4$} \\
\hline & Grup İçi & 7014.75 & 312 & 22.48 & & & \\
\hline \multirow{2}{*}{$\begin{array}{l}\text { Saplantılı } \\
\text { Bağlanma }\end{array}$} & Gruplararas1 & 4.59 & 3 & 1.53 & \multirow{2}{*}{0.07} & \multirow{2}{*}{0.97} & \multirow{2}{*}{ - } \\
\hline & Grup İçi & 6633.28 & 312 & 21.26 & & & \\
\hline
\end{tabular}

Tablo 5 incelendiğinde annelerin eğitim düzeyi açısından güvenli, korkulu ve saplantılı bağlanma stilleri açısından anlamlı bir fark olmadığı ancak kayıtsız bağlanma stilinde bir farklılaşma olduğu görülmektedir $\left(\mathrm{F}_{(3 ; 312)}=3.41 ; \mathrm{p}<.05\right)$. Farkın kaynağını belirlemek amacıyla yapılan benferoni testine göre farkın kaynağ1 annesi ilkokul mezunu olan ergenlerle annesi üniversite mezunu olan ergenler arasındaki farktır. Annesi üniversite mezunu olan ergenlerin kayıtsız bağlanma puanları annesi ilkokul mezunu olan ergenlerden daha yüksektir ve bu durum babalardaki sonuçlar ile benzerdir.

Tablo 6. Ergenlerin devam ettikleri okul türlerine göre bağlanma stilleri puanlarının incelenmesine ilişkin tek yönlü varyans analizi sonuçları

\begin{tabular}{|c|c|c|c|c|c|c|c|}
\hline & & KT & sd & $\mathrm{KO}$ & $\mathrm{F}$ & $\mathrm{p}$ & İkili karşılaştırma \\
\hline \multirow{2}{*}{ Güvenli Bağlanma } & Gruplararas1 & 84.88 & 4 & 21.22 & \multirow{2}{*}{1.15} & \multirow{2}{*}{.33} & \multirow{2}{*}{-} \\
\hline & Grup İçi & 5753.25 & 311 & 18.49 & & & \\
\hline \multirow{2}{*}{ Korkulu Bağlanma } & Gruplararas1 & 71.22 & 4 & 17.80 & \multirow{2}{*}{0.74} & \multirow{2}{*}{.56} & \multirow{2}{*}{-} \\
\hline & Grup İçi & 7439.75 & 311 & 23.92 & & & \\
\hline \multirow{2}{*}{ Kayıtsız Bağlanma } & Gruplararas1 & 42144 & 4 & 105.36 & \multirow{2}{*}{4.80} & \multirow{2}{*}{.00} & \multirow[b]{2}{*}{$2-3$} \\
\hline & Grup İçi & 6823.29 & 311 & 21.94 & & & \\
\hline \multirow{2}{*}{ Saplantılı Bağlanma } & Gruplararas1 & 212.59 & 4 & 53.14 & \multirow{2}{*}{2.57} & \multirow{2}{*}{.04} & \multirow[b]{2}{*}{$2-3$} \\
\hline & Grup İçi & 6425.28 & 311 & 20.66 & & & \\
\hline
\end{tabular}

Tablo 6'ya bakıldığında okul türleri açısından güvenli ve korkulu bağlanma stilleri açısından anlamlı bir fark olmadığ 1 görülürken, kayıtsız $\left(\mathrm{F}_{(4,311)}=4.80 ; \mathrm{p}<.01\right)$ ve saplantılı bağlanma $\left(\mathrm{F}_{(4,311)}=2.57 ; \mathrm{p}<.05\right)$ stilleri açısından anlamlı farklılıklar olduğu görülmektedir. Farkın kaynağını belirlemek için yapılan benferoni testine göre farkın kaynağı fen lisesi ile meslek lisesi öğrencileri arasındaki farktır. Hem kayıtsız bağlanma 
hem saplantılı bağlanma stillerinde fen lisesi öğrencilerinin puanlarının meslek lisesi öğrencilerin daha yüksek olduğu belirlenmiştir.

\section{TARTIȘMA ve SONUÇ}

Araştırma sonuçları internet bağımlılığı ile saplantılı bağlanma stili arasında anlamlı bir ilişki olduğunu göstermektedir. Literatüre bakıldığında, güvensiz bağlanma stilleri ile internet bağımlılı̆̆ının ilişkili olduğunu gösteren araştırma sonuçları olduğu görülmektedir (Lei \& Wu, 2007; Morsünbül, 2014; Savc1 \& Aysan, 2016; Shin, Kim \& Jang, 2011). Sheldon, Abad ve Hirsch (2011) de aşırı Facebook kullanımı ile bağlanma stilleri arasındaki ilişki olduğu bulgusuna ulaşmıştırlar. Güvensiz bağlanma stillerindeki bireylerin benlik ve başkaları modellerinden en az bir tanesi olumsuzdur ve bu durum ihtiyaç duydukları yakınlığı sağlamalarına engel olabilmektedir. Bu bireyler reddedilme, beğenilmeme korkusu ile anlamlı ilişkiler kurmakta zorlanmakta, bu konuda girişimde bulundukları kişileri ise 1srarcı tavırları ile kendilerinden uzaklaştırabilmektedirler (Bartholomew \& Horowitz, 1991). Bu durum nedeniyle yüz yüze olmadıkları sanal iletişim ortamları saplantılı bağlanan bireyler için cazip olabilmekte, reddedilme korkusu yaşamadan üstelik farklı farklı kimliklere bürünerek tekrar tekrar iletişim kurma olanağı sunmaktadır. Bu durumun saplantılı bağlanan bireyleri internet bağımlılığına daha yatkın hale getirdiği söylenebilir.

Araştırma sonuçları cinsiyet değişkeni açısından sadece kayıtsızbağlanma stilinde kadınlarınerkek öğrencilerden daha yüksek puan ortalamasına sahip olduğunu göstermektedir. Alanyazına bakıldığında bu konuda araştırma sonuçlarının farklılık gösterdiği görülmektedir. Sümer ve Güngör (1999) yürüttükleri çalışmada kızların korkulu bağlanma puanlarının erkeklerden daha yükssek olduğu sonucuna ulaşmıştırlar. Saymaz (2003) da üniversite öğrencileri ile yürüttüğü çalışmada erkek öğrencilerin güvenli bağlanma puanlarının kızlardan daha yüksek, korkulu bağlanma puanının ise kızlarda daha yüksek olduğu sonucuna ulaşmıştır. Benzer bir sonuca ulaşan Onur (2006) tarafından yapılan araştırmada bağlanma stillerinin cinsiyete göre farklılaştı̆̆ sonucuna ulaşılmıştır. Araştırmanın sonucuna göre; erkek ergenler güvenli bağlanma stiline, kız ergenler ise güvensiz bağlanma stiline (korkulu, kayıtsız, saplantılı) sahiptirler. Karakuş (2012) ise yaptı̆̆ çalışmada erkeklerin güvenli bağlanma stiline ilişkin puanlarının kızlardan daha yüksek olduğunu, diğer stillerde ise anlamlı bir farklılık olmadığını bulgulamıştır. Damarlı (2006) ve Erözkan (2004) ise erkeklerin güvenli bağlanma stili puan ortalamalarının kızların puan ortalamalarından daha yüksek olduğu diğer stiller açısından anlamlı bir farklılık olmadığ sonucuna ulaşmıştırlar. IşınsuHalat (2009) ise korkulu bağlanma stilinde kadınların daha yüksek puan ortalamasına sahip olduklarını diğer stiller açısından anlamlı bir fark olmadığını bulgulamıştır. Yıldız (2008) de benzer bir şekilde kızların korkulu bağlanma stili puanlarının erkeklerden daha yüksek, erkeklerin ise güvenli bağlanma puanlarının daha yüksek olduğunu bulgulamıştırlar. Keler (2008) ise kayıtsız ve korkulu bağlanma stilleri açısından cinsiyetler arasında anlamlı bir fark olmadığını, güvenli ve saplantılı bağlanma stilinde erkeklerin kadınlardan daha yüksek puan ortalaması olduğunu bulgulamıştır. Cebeci (2009) tarafından yapılan araştırmada ise, erkeklerin kızlara göre daha güvenli bağlandıkları görülmüştür. Taşkaya (2019) ise, kurum bakımında olan kız ve erkek ergenlerin bağlanma stillerinin cinsiyet değişkeni açısından farklılaştı̆̆ı, kız ergenlerin Kaygıl1-Kararsız bağlanma puan ortalamasının erkeklerden daha yüksek olduğu sonucuna ulaşmıştır. Bu araştırma sonuçlarının aksine bir sonuca ulaşan Haliloğlu (2008) ise, kızların erkeklere kıyasla daha yüksek düzeyde güvenli bağlanma stiline sahip olduklarını bulgulamıştır. Tüm bunlardan farklı olarak Atabay (2019) yürüttüğü çalışmada, bağlanma stillerinin cinsiyet açısından farklılaşmadığı sonucuna ulaşmıştır. Genel olarak bakıldığında kızların olumsuz bağlanma konusunda erkeklerden daha yüksek puanlar aldıkları görülmektedir. Bu durumun kültürle ilişkili olduğu söylenebilir. Türk kültüründe kız çocuklarına erkeklere göre daha korumacı davranılmakta ve erkekler kadar rahat sosyalleşme imkânı tanınmamaktadır. Araştırmanın çalışma grubunun ergenlerden oluştuğu düşünüldüğünde bu korumacı yaklaşımın üzerlerinde etkili olacağı söylenebilir. Bu korumacı yaklaşım kız çocuklarını dış tehlikelerden koruma amacıyla yapılıyor olsa da tüm bu tehlike söylemlerinin kız çocuklarının çevreye karşı güven 
konusunda problem yaşamalarına yol açabilmektedir. Bu durum, yakın ilişkiler konusunda daha tutuk ve savunmacı yaklaşmalarına ve güvensiz bir bağlanma örüntüsü geliştirmelerine yol açabilmektedir.

Araştırmanın bir değişkeni olan okul türü açısından ergenlerin bağlanma stilleri farklılaşmaktadır. Hem kayıtsız bağlanma hem saplantılı bağlanma stillerinde fen lisesi öğrencilerinin puanlarının meslek lisesi öğrencilerin daha yüksek olduğu belirlenmiştir. Fen lisesi öğrencilerinin akademik açıdan daha hırslı olmaları, sosyalleşmeye daha az zaman ayırdıkları ve sosyal ilişkiler konusunda sınırlılıklara sahip oldukları ve yalnızlık konusunda sorun yaşadıkları çeşitli araştırmalarda ifade edilmektedir (İşçioğlu, 2020; Yabanc1, 2019). Bu durum, güvenli bağlanma konusunda sorun yaşamalarını açıklayan bir faktör olarak kabul edilebilir. Meslek lisesi öğrencilerinin akademik beklentilerinin daha düşük olması, bu konuda üzerlerinde daha az baskı hissetmeleri ve uygulamaya yönelik derslerin sosyalleşmelerini de olumlu etkileyeceği düşünüldüğünde aralarındaki bu fark anlaşılır hale gelmektedir. $\mathrm{Bu}$ durumun ebeveyn yaklaşımları ile de ilgili olacağı söylenebilir. Fen lisesi öğrencilerinin ailelerinin sosyalleşme konusunda çocuklarını sınırlandıracağı ve daha fazla ders başında zaman geçirmeye teşvik edeceği, bu yaklaşımın ve sosyallikten uzak olmanın da bu sonuç üzerinde etkili olacağı söylenebilir. Literatüre bakıldığında bu araştırma ile benzer sonuçlara ulaşan araştırmalar olduğu görülmektedir (Göktepe, 2015; Onur, 2006).

Ergenlerin bağlanma stilleri anne ve babanın eğitim durumuna göre incelenmiş ve farklılaşmalar olduğu görülmüştür. Annesi üniversite mezunu olan ergenlerin kayıtsız bağlanma puanları annesi ilkokul mezunu olan ergenlerden daha yüksek olduğu, babası ilkokul mezun olan ergenlerin güvenli bağlanma boyutundan aldıkları puanların babası lise mezunu olanlardan daha yüksek olduğu, babası lise mezunu olanların ise kayıtsız bağlanma boyutundan aldıkları puanın daha yüksek olduğu görülmektedir. Üniversite mezunu annelerin iş hayatında daha aktif olması, dışarıda daha fazla zaman geçirmeleri ve kalan zamanda ev ile ilgili sorumlulukları nedeniyle çocukları ile paylaştıkları nitelikli zamanın daha az olmasından kaynaklandığı söylenebilir. Çalışan annelerin çocukları genellikle aile büyükleri veya bakıcılar ile büyümekte ve bağlanma figürü çocuğun hayatında değişkenlik gösterebilmektedir. Literatüre bakıldığında anne babanın eğitim durumuna göre bağlanma stillerinin farklılaştığı sonucuna ulaşan araştırma sonuçları olduğu gibi (Cebeci, 2009; Onur, 2006; Saymaz, 2003; Sumbas \& Sezer, 2017) eğitim durumu açısından bir fark olmadığı bulgusuna ulaşan araştırma sonuçları olduğu da görülmektedir (Bekir, Arbaş \& Aydın, 2018; Göktepe, 2015).

Sonuç olarak araştırma bulgularına göre ergenlerin bağlanma stilleri ile internet bağımlılık düzeyleri arasında anlamlı bir ilişki olduğu görülmektedir. Saplantılı bağlanma stili ile internet bağımlılığı arasında doğrusal ve anlamlı bir ilişki vardır. Ergenlerin bağlanma stilleri cinsiyet açısından anlamlı farklılıklar göstermektedir. Kadınların kayıtsız bağlanma stili puan ortalamaları erkeklerden daha yüksek olarak bulunmuştur. Anne - baba eğitim düzeyi açısından da anlamlı sonuçlar olduğu görülmektedir. Babası ilkokul mezunu olanlarla lise mezunu olan ergenlerin hem güvenli hem de kayıtsız bağlanma stilleri arasında anlamlı farklılıklar olduğu, anne eğitim düzeyi ilkokul ve üniversite mezunu olan ergenlerin kayıtsız bağlanma düzeyleri açısından anlamlı farklılıklar olduğu bulgulanmıştır. Çıkan fark eğitim düzeyi yüksek olan anne babaların lehinedir. Ayrıca okul türü açısından da ergenlerin bağlanma stilleri farklılaşmaktadır. Meslek lisesi ve Fen lisesi öğrencilerinin hem kayıtsız hem de saplantılı bağlanma stilleri arasında anlamlı farklılıklar olduğu görülmektedir. Fen lisesi öğrencilerinin puanları her iki bağlanma stilinde de meslek lisesi öğrencilerinden daha yüksektir.

\section{Araştırmanın Sınırlılıkları ve Gelecek Çalışmalar için Öneriler}

$\mathrm{Bu}$ araştırma Trabzon merkezdeki lise öğrencileri ile sınırlıdır. Daha geniş ölçekli çalışmalarda farklı yaş gruplarında, bağlanma stilleri ve internet bağımlılığını yordayıcı değişkenlerin belirlenmesine yönelik çalışmaların yapılması, internet bağımlılığı ile ilgili nitel araştırma yaklaşımıyla yapılacak çalışmalarla konuya farklı bir boyut kazandırılarak derinlemesine incelemeler yapılması yararlı olacaktır. Bu araştırmada bağlanma stillerinin cinsiyet, okul türü, anne baba eğitim düzeyi değişkenleri açısından 
farklılaşıp farklılaşmadığı üzerinde durulmuştur. Gelecekte yapılması planlanan araştırmalarda farklı demografik değişkenlerin (akademik not ortalaması, kardeş sayısı, ekonomik durum vb.) üzerinde durulması konunun daha iyi anlaşılmasına katkı sağlayabilir.

\section{Çatışma Beyanı}

Yazarlar makale üzerinde eşit hakka sahiptirler ve herhangi bir çıkar çatışması söz konusu değildir.

\section{KAYNAKLAR}

Ainsworth, M. D. S. (1991). Attachments and other affectional bonds across the life cycle. In C. M. Parkes, J. Stevenson-Hinde \& P. Marris (eds.). Routledge.

Allen, J. P. \& Land, D. (1999). Attachment in adolescence. Handbook of attachment theory. Research and Clinical Applications. Guilford Press.

Atabay, E. (2019). Üniversite Öğrencilerinde Mizah ve İletişim Becerilerinini Bağlanma Stilleriyle İlişkisi (Yayımlanmamış Yüksek Lisans Tezi). Üsküdar Üniversitesi Sosyal Bilimler Enstitüsü Klinik Psikoloji Anabilim Dalı.

Bar-Haim, Y., Dan, O., Eshel, Y. \& Sagi-Schwartz, A. (2007). Predicting Children's Anxiety From Early Attachment Relationships. Journal of Anxiety Disorders, 21, 1061-1068.

Bartholomew, K. \&Shaver, P. R., (1998). “Measures of Attachment: Do they converge? (Ed.) J.A. Simpson”, W.S. Rholes Attachment theory and close relationships, GuilfordPress, 25-45.

Bartholomew, K. \&Horowitz, L. M. (1991) Attachment Styles Among Young Adults: A Test of a Four-Category Model. Journal of Personality and Social Psychology, 61(2), 226-24.

Bekir, H., Arbaş, G. \& Aydın, R. (2018). Sosyal Dezavantajlı Bölgedeki Ortaokul Öğrencilerinin Anneye Bağlanma ve Sosyal Destek Alg1sı. Dicle Üniversitesi Ziya Gökalp Dergisi, 33, 79-90. http://dx.doi.org/10.14 582/DUZGEF.1885

Bowlby, J. (1969). Attachmentand Loss: Vol. 1, Attachment. Basic Books.

Bowlby J. (2012). Bağlanma (Çev.T. V. Soylu). Pinhan Yayınları.

Büyüköztürk, Ş., Çokluk, Ö., \& Şekercioğlu, G. (2011). Sosyal bilimler için istatistik. Pegem Akademi.

Büyüköztürk, Ş. (2014). Sosyal Bilimler İ̧̧in Veri Analizi El Kitabı (19.Basım). Pegem Akademi.

Cebeci-Turan, S.C. (2009). Tam Aileye ve Tek Ebeveyne Sahip Ailelerden Gelen 7-12 Yaşları Arasındaki Çocukların Bağlanma Stilleri ve Kaygı Durumları Arasındaki İlişki (Yayımlanmamış Yüksek Lisans Tezi). Maltepe Üniversitesi Sosyal Bilimler Enstitüsü Klinik Psikoloji Anabilim Dalı.

Chou C, Condron, L. \&Belland, J C (2005) A Review of the Research on İnternet Addiction. Educational Psychology Review, 17(4), 363-388.

Cao F, Su L, Liu T. \& Gao, X (2007). The Relationship Between İmpulsivity and Internet Addiction in a Sample of Chinese Adolescents. European Psychiatry, 22, 466-471.

Çetinkaya, M. (2013). İlköğretim Öğrencilerinde İnternet Bă̆ımlılı̆̆ının İncelenmesi (Yayımlanmamış Yüksek Lisans Tezi). Dokuz Eylül Üniversitesi Eğitim Bilimleri Enstitüsü Rehberlik ve Psikolojik Danışmanlık Bilim Dalı.

Damarlı Ö. (2006). Ergenlerde Toplumsal Cinsiyet Rolleri, Bağlanma Stilleri ve Benlik Kavramı Arasındaki Ilişkiler (Yayımlanmamış Yüksek Lisans Tezi). Ankara Üniversitesi Sosyal Bilimler Enstitüsü Sosyal Psikoloji Anabilim Dalı.

Davis, R. A. (2001). A Cognitive-Behavioral Model for Pathological İnternet Use (PIU). Computers in Human Behavior, 17(2), 187-195

Doğan, A. (2013). İnternet Bağımlı̆̆g Yaygınlı̆̆g (Yayınlanmamış Yüksek Lisans Tezi). Dokuz Eylül Üniversitesi Eğitim Bilimleri Enstitüsü Aile Eğitimi ve Danışmanlığı Anabilim Dalı.

Donohue, B., Urgelles, J. \& Fayeghi, J. (2013). Adolescent substance abuse. Springer.

Erikson, EH (1993). Childhood and society. Norton. https://doi.org/10.1002/1520-6807(199507)32:3<243::AIDPITS2310320315>3.0.CO;2-4 
Erözkan, A. (2004). Lise Öğrencilerinin Bağlanma Stilleri ve Yalnızlık Düzeylerinin Bazı Değişkenlere Göre İncelenmesi. Sosyal Bilimler Enstitüsü Dergisi, 2(4).155-175.

Fraenkel, J.R., Wallen, N.E. \& Hyun, H.H. (2015). How to design and evaluate research in education (9th edition). McGraw Hill Education.

Göktepe, G. (2015). Liseli Ergenlerde Bağlanma Stilleri, Kendilik Algısı ve Kişiler Arası İlişkilerin İncelenmesi (Yayınlanmamış Yüksek Lisans Tezi). Haliç Üniversitesi Sosyal Bilimler Enstitüsü Psikoloji Anabilim Dalı.

Griffin, D., \& Bartholomew, K. (1994). Models of the Self and Other: Fundamental dimensions underlying measures of adultattachment. Journal of Personality and Social Psychology, 67, 430-445.

Griffiths, M. (2005). A 'Components' Model of Addiction Within a Biopsychosocial Framework. Journal of SubstanceUse, 10(4), 191-197. http://dx.doi.org/10.1080/14659890500114359

Haliloglu, S. (2008). Ortaöğretim 9. sınıf Öğrencilerinin Yalnızlık Düzeyleri, Bă̆lanma Biçimleri ve İşlevsel Olmayan Tutumları Arasındaki İlişkinin İncelenmesi (Malatya İli Örneği) (Yayımlanmamış Yüksek Lisans Tezi). İnönü Üniversitesi Sosyal Bilimler Enstitüsü Eğitim Bilimleri Anabilim Dalı.

Hamarta, E. (2004). Üniversite Öğrencilerinin Yakın İlişkilerindeki Bazı Değişkenlerin (Benlik saygısı, Depresyon ve Saplantılı Düşünme) Bağlanma Stilleri Açısından İncelenmesi (Yayımlanmamaış Doktora Tezi). Selçuk Üniversitesi Sosyal Bilimler Enstitüsü Eğitim Bilimleri Anabilim Dalı.

Işınsu-Halat, M. (2009). Yatırım Kuramı Bağlamında Evli Çiftlerde Uyum, Nedensel ve Sorumluluk Yüklemeleri ile Yalnızlık Arasındaki Bağlantılar (Yayımlanmamış Doktora Tezi). Ankara Üniversitesi Sosyal Bilimler Enstitüsü Psikoloji Anabilim Dal1.

İşçioğlu, E. (2020). Lise Öğrencilerinin Cinsiyet, Okul türü ve Bilişsel Esneklik Düzeylerine Göre Sosyal Becerilerinin Incelenmesi (Yayımlanmamış Yüksek Lisans Tezi). Çağ Üniversitesi Sosyal Bilimler Enstitüsü Psikoloji Anabilim Dalı.

Karakuş, Ö. (2012). Ergenlerde Bağlanma Stilleri ve Yalnızlık Arasındaki İlişki. Toplum ve Sosyal Hizmet, 23(2), 3346.

Karasar, N. (2009). Bilimsel araştırma yöntemleri (20. Baskı). Nobel Yayın Dağıtım.

Keler, H. (2008). Liseli Ergenlerin Transaksiyonel Analiz Ego Durumları ile Bağlanma Stilleri Arasındaki İlişkinin incelenmesi (Yayımlanmamış Yüksek Lisans Tezi). Marmara Üniversitesi Eğitim Bilimleri Enstitüsü Eğitim Bilimleri Anabilim Dalı.

Ko C. H., Yen J. Y., Chen S. H., Yang M. J., Lin H. C. \& Yen C. F. (2009). Proposed Diagnostic Criteria and the Screening and Diagnosing Tool of Internet Addiction in College Students. Comprensive Psychiatry, 50, 378384. https://doi.org/10.1016/j.comppsych.2007.05.019

Kulaksızoğlu, A. (2013). Ergenlik psikolojisi (4. Basım). Remzi.

Kutlu, M., Savcı, M., Demir, Y. \& Aysan, F. (2016). Young İnternet Bağımlılı̆̆ Testi Kısa Formunun Türkçe Uyarlaması: Üniversite Öğrencileri ve Rrgenlerde Geçerlilik ve Güvenilirlik Çalışması. Anadolu Psikiyatri Dergisi, 17, 69-76. http://dx.doi.org/10.5455/apd.190501

Lei, L., \& Wu, Y. (2007). Adolescents’ Paternal Attachment and Internet Use. Cyberpsycology\&Behavior, 10,633639.

Milani, L., Osualdella, D. \& Blasio, P. D. (2009). Quality of Interpersonal Relationships and Problematic Internet Use in Adolescence. CyberPsychology\&Behavior,12(6), 681-684. https://doi.org/10.1089/cpb.2009.0071

Morsünbül, Ü. (2014). İnternet Bağımlılığının Bağlanma Stilleri, Kişilik Özellikleri, Yalnızlık ve Yaşam Doyumu ile İlişkisi. International Journal of Human Sciences, 11(1), 357-372. http://dx.doi.org/10.14687/ijhs.v11i1.2727

Muuss, R. (1990). Adolescent behavior and society. Forthedition. In: McGraw-Hill Publishing Company.

Odac1, H. \& Kalkan, M. (2010). Problematic Internet Use, Loneliness and Dating Anxiety Among Young Adult University Students. Computers \& Education 55(3):1091-1097. Doi: 10.1016/j.compedu.2010.05.006

Onur, N. (2006). Lise Öğrencilerinin Bağlanma Stilleri ile Atılganlık Düzeyleri Arasındaki İlişki. (Yayımlanmış Yüksek Lisans Tezi). Marmara Üniversitesi Eğitim Bilimleri Enstitüsü Rehberlik ve Psikolojik Danışmanlık Anabilim Dalı

Parman, T. (2008). Ergenlik ya da merhaba hüzün (3. Bask1). Bağlam. 
Pawlikowski, M., Altstötter-Gleich, C., \&Brand, M. (2013). Validation and Psychometric Properties of a Short version of Young's Internet Addiction Test. Computers in Human Behavior, 29(3), 1212-1223. https://doi. org/10.1016/j.chb.2012.10.014

Sağlık Bakanlığı (2018). Dijital Oyun Bă̆ımlılı̆̆ Çalıştayı Sonuç Raporu. https://www.guvenliweb.org.tr/dosya/usxdh.pdf

Savci, M., \& Aysan, F. (2017). Relationship Between İmpulsivity, Social Media Usage and Loneliness. Educational Process: International Journal, 5(2), 106-115. http://dx.doi.org/10.12973/ edupij.2016.52.2

Saymaz, İ. (2003). Üniversite Öğrencilerinin Kişilerarası İlişkileri ve Bağlanma Stilleri Arasındaki İlişkinin Incelenmesi. (Yayınlanmamış Yüksek Lisans Tezi). Istanbul Üniversitesi Sosyal Bilimler Enstitüsü Eğitim Bilimleri Anabilim Dalı.

Sheldon, K. M., Abad, N., \& Hirsch, C. (2011). A Two-Processview of Facebook use and Relatedness NeedSatisfaction: Disconnection Drives use, and Connection Rewards it. Journal of Personality and Social Psychology, 100,766-775.

Shin, S. E., Kim, N. S., \&Jang, E. Y. (2011). Comparison of Problematic İnternet and Alcohol use and Attachment Styles Among İndustrial Workers in Korea. CyberPsychology, Behavior, and Social Networking, 14(11), 665672. http://dx.doi.org/10.1089/cyber.2010.0470

Sumbas, E. \& Sezer, Ö. (2017). Ortaokul Öğrencilerinde Anne Babaya Bağlanmanın İncelenmesi. Ege Eğitim Dergisi, 18 (1): 288-310.

Sümer, N. \& Güngör, D. (1999) Yetişkin Bağlanma Stilleri Ölçeklerinin Türk Örneklemi Üzerinde Psikometrik Değerlendirilmesi ve Kültürlerarası Bir Karşılaştırma. Türk Psikoloji Dergisi, 14, 71-106.

Tokunaga, R. S. \&Rains, S. A. (2010). An Evaluation of two Characterizations of the Relationships Between Problematic Internet Use Time Spentusing the Internet and Psychosocial Problems. Human Communication Research, 36(4), 512-545.

Tangney, J. P., Baumeister, R. F. \& Boone, A. L. (2004). High Self-Control Predicts Good Adjustment, Less Pathology, Better Grades, and İnterpersonal Success. Journal of Personality, 72, 271-322.

Taşkaya, R. (2019). Ergenlerin Bağlanma Stilleri Sorumluluk Duygu ve Davranışı ile Kaygı Düzeyleri Arasındaki İlişkinin Incelenemesi (Yayımlanmamış Yüksek Lisans Tezi). Karabük Üniversitesi Sağlık Bilimleri Enstitüsü Çocuk Gelişimi ve Eğitimi Anabilim Dalı.

Vertue, F. M. (2003). From Adaptive Emotion to Dysfunction: An Attachment Perspective on Social Anxiety dDsorder. Personality and socail Psychology Review, 7(2),170-191.

Yabancı, C. (2019). Lise Öğrencilerinin Sosyal Medyaya İlişkin Tutumları ile Narsisizm ve Yalnızlık Düzeyleri Arasındaki İlişkinin İncelenmesi (Yayınlanmamış Yüksek Lisans Tezi). Bursa Uludağ Üniversitesi Eğitim Bilimleri Enstitüsü Eğitim Bilimleri Anabilim Dalı.

Yavuzer, H. (2011). Çocuk psikolojisi. Remzi Kitabevi.

Yıldız, C. (2008). Üniversite Öğrencilerinin Geçmişte Yaşadıkları Ayrılık Kaygısı ile Bağlanma Stilleri Arasındaki İlişkinin Incelenmesi Üzerine Bir Araştırma (Yayımlanmamış Yüksek Lisans Tezi). Selçuk Üniversitesi Sosyal Bilimler Enstitüsü Eğitim Bilimleri Anabilim Dalı.

Young, K. S. (1998). Internet Addiction: The Emergence of a New Clinical Disorder. CyberPsychol\&Behavior, 1, 237-244. 